Jerzy Boryczka, Maria Stopa-Boryczka

\title{
DEFORMATION OF THE FIELD OF AIR TEMPERATURE DUE TO THE RELIEF OF POLAND
}

The present paper attempts a distinction between temperature changes conditioned by geographical position (angle of sunrays, length of daytime, distance from the Atlantic) and the changes conditioned by heights above the sea level in Poland (Stopa-Boryczka, Boryczka 1976, 1984, 1986).

The determination of the deformation of temperature field due to relief, has been approximated with polynomial of the following terms:

$$
T=F(\varphi, \lambda, H)=a_{0}+\sum_{\alpha=1}^{\xi} \sum_{\beta=1}^{\alpha} \sum_{\gamma=1}^{\beta} a_{\alpha \beta \gamma} \varphi^{\alpha-\beta+1} \lambda^{\beta-\gamma} H^{\gamma-1}
$$

in relation to latitude $\varphi$ and longitude $\lambda$ as well as height above the sea level $\mathrm{H}$ in $\mathrm{hm}$.

Field gradient grad $T=\left\{\frac{\partial F}{\partial \varphi}, \frac{\partial F}{\partial \lambda}, \frac{\partial F}{\partial \mathrm{H}}\right\}-$ is a vector whose coordinates are partial derivatives of approximating function $F(\varphi, \lambda, H)$ :

$\frac{\partial T}{\partial \varphi}-$ meridional gradient, ${ }^{\circ} \mathrm{C} / 1^{\circ}$

$\frac{\partial T}{\partial \lambda}$ - parallel gradient, ${ }^{\circ} \mathrm{C} / 1^{\circ}$

$\frac{\partial T}{\partial \mathrm{H}}$ - hypsometric gradient, ${ }^{\circ} \mathrm{C} / 100 \mathrm{~m}$

Transformation of the original data:

$$
\Phi=1.111 \varphi, \Lambda=1.111 \lambda \cos \varphi
$$

yields horizontal gradient

$$
\vec{\Gamma}=\left[\frac{\partial F}{\partial \Phi}, \frac{\partial F}{\partial \Lambda}\right]
$$

measured in ${ }^{\circ} \mathrm{C} / 100 \mathrm{~km}$. 
Its coordinates $\frac{\partial T}{\partial \Phi}, \frac{\partial T}{\partial \Lambda}$ - consist of temperature increases by $100 \mathrm{~km}$ to the north and to the east.

Horizontal gradient $\vec{\Gamma}$ of temperature field according to climate zones should be directed toward the south $(S)$. Temperature field deformation due to the inflow of maritime polar air masses over Poland (the influence of the Atlantic Ocean) is defined by the angle between vector $\vec{\Gamma}$ and meridian plane (astronomical azimuth a) Gradient $\vec{\Gamma}$ deflection from NS direction by angle $a$ indicates:

$a<\pi$ (west) - the influence of martitime polar air masses (oceanic tendency) $a>\pi$ (east) - increase in continental climate features (continental tendency).

In order to distinguish temperature field deformation due to relief, Taylor series $T=f(\Phi, \Lambda)$ has been applied only in relation to $\Phi, \Lambda-$ height above the sea level $H$ has been disregarded.

If horizontal gradient

$$
\vec{\gamma}=\left[\frac{\partial f}{\partial \Phi}, \frac{\partial f}{\partial \Lambda}\right]
$$

deflects by angle $A$ from NS direction, the field deformation is measured by the difference $A-a-$ angle between vectors $\vec{\gamma}, \vec{\Gamma}$.

Field deformation coefficient will consist of the relation

$$
D=\frac{|a-A|}{\pi} \cdot 100 \%
$$

Deformation of air temperature field due to relief may be defined as follows:

$$
\Delta T=T_{0}-T=-\frac{\partial T}{\partial H} \cdot H
$$

where $\frac{\partial T}{\partial H}$ is local hypsometric gradient, that is in point $\left(\varphi_{i}, \lambda_{i} H_{i}\right)$.

The reduction of temperature field to the sea level $H=0, T=T_{0}$ is done by adding local reduction correction $\Delta T$ to measured temperature $T_{i}$ or $T$ derived from polynomial of 1 .

The first terms $(\xi=1)$ of developing temperature field into Taylor series are well known hyperplane and regression plane equations

$$
\begin{gathered}
T=F(\Phi, \Lambda, H)=a_{0}+a_{1} \Phi+a_{2} \Lambda+a_{3} H \\
T=f(\Phi, \Lambda)=A_{0}+A_{1} \Phi+A_{2} \Lambda
\end{gathered}
$$

These are special cases of three- and two-dimensional fields with constant gradients: $\vec{\Gamma}=\left[a_{1}, a_{2}\right]=$ const, $\vec{\gamma}=\left[A_{1}, A_{2}\right]=$ const. Thus field deformation 
measure is represented by an angle between these horizonatal gradients; they

are constant for the entire area of Poland.
Deformation coefficient $D$ may also be calculated by taking $\vec{\gamma}=\left[\frac{d f}{d \Phi}\right.$, $\left.\frac{d f}{d \Lambda}\right]=\left[\alpha_{1}, \alpha_{2}\right]$ according to simple regressions $T=\alpha_{01}+\alpha_{1} \Phi, T=\alpha_{02}+\alpha_{2} \Lambda$

The most characteristic features of air temperature field in Poland are represented by the following profiles: $T(\Phi)-$ meridional, $T(\Lambda)-$ parallel, $T(\mathrm{H})$ - hypsometric, defined by polynomials of the 4th order with respect to $\Phi, \Lambda, H$ (Tab. 1, Fig. 1, 3). They define the respective temperature fields as affected and deformed by Poland's relief.

Table 1

Profiles: meridional $T(\Phi)$, parallel $T(\Lambda)$, hypsometric $T(H)$ of air temperature in Poland

$$
\begin{array}{ll}
\text { Oct-March } & T=-19.56+0.000000 \Phi+0.000008 \Phi^{2}+0.000368 \Phi^{3}-0.000005 \Phi^{4} \\
\text { April-Sept } & T=-36.69+0.000000 \Phi+0.000022 \Phi^{2}+0.000365 \Phi^{3}-0.000012 \Phi^{4} \\
\text { Jan-Dec } & T=-27.99+0.000000 \Phi+0.000015 \Phi^{2}+0.000664 \Phi^{3}-0.000008 \Phi^{4} \\
\text { Oct-March } & T=-5.414+0.03819 \Lambda+0.3400 \Lambda^{2}-0.03869 \Lambda^{3}+0.001121 \Lambda^{4} \\
\text { April-Sept } & T=-4.604+0.07584 \Lambda+0.6754 \Lambda^{2}-0.07123 \Lambda^{3}+0.002077 \Lambda^{4} \\
\text { Jan-Dec } & T=-4.281+0.05606 \Lambda+0.4993 \Lambda^{2}-0.05407 \Lambda^{3}+0.001598 \Lambda^{4} \\
\text { Oct-March } & T=1.663-0.253 \mathrm{H}+0.006889 \mathrm{H}^{2}-0.001280 \mathrm{H}^{3}+0.000035 \mathrm{H}^{4} \\
\text { April-Sept } & T=13.58+0.643 \mathrm{H}+0.2388 \mathrm{H}^{2}+0.01780 \mathrm{H}^{3}-0.000440 \mathrm{H}^{4} \\
\text { Jan-Dec } & T=7.62+0.1906 \mathrm{H}-0.1140 \mathrm{H}^{2}+0.008057 \mathrm{H}^{3}-0.000196 \mathrm{H}^{4}
\end{array}
$$

Within merdional profile $T(\Phi)$ temperature rises with the latitude with regards to terrain lowering towards the north.' Temperature on the southern border of Poland averages: cool period (October-March) $-0.1^{\circ} \mathrm{C}$, warm period (April-September) $12.5^{\circ} \mathrm{C}$. Close to the northern border the temperatures are higher: cool period $1.4^{\circ} \mathrm{C}$, warm period $14.0^{\circ} \mathrm{C}$.

Parallel profiles $T(\Lambda)$ differ in October-March, April-September periods. In cool periods, the western part of Pöland averages temperatures higher than the mean temperature for the country $\left(1.0^{\circ} \mathrm{C}\right)$, while the eastern part - lower. In the warm period the lowest temperatures are recorded along the western border $\left(12.4^{\circ} \mathrm{C}\right)$, and the highest in the east $\left(15.0^{\circ} \mathrm{C}\right)$.

In vertical profile $T(H)$ air temperature of both periods drops with the increase of altitude: cool period - from $1.5^{\circ} \mathrm{C}$ at altitudes $H=0$ to $-5.0^{\circ} \mathrm{C}$ at $H=2000 \mathrm{~m}$, warm period - from $14^{\circ} \mathrm{C}$ at the sea level to $3^{\circ} \mathrm{C}$ at the altitude about $2000 \mathrm{~m}$. In the warm period temperature drops related to increase in altitude are larger than during the cool periods.

The dynamics of change of temperature field is indicated by gradient profiles: $\frac{d T}{d \Phi}$ (south-north), $\frac{d T}{d \Lambda}$ (west-east), $\frac{d T}{d H}$ (vertical) - derivative of approximating functions $T(\Phi), T(\Lambda), T(H) \backslash$ (Fig. 1, 2, 3,). 

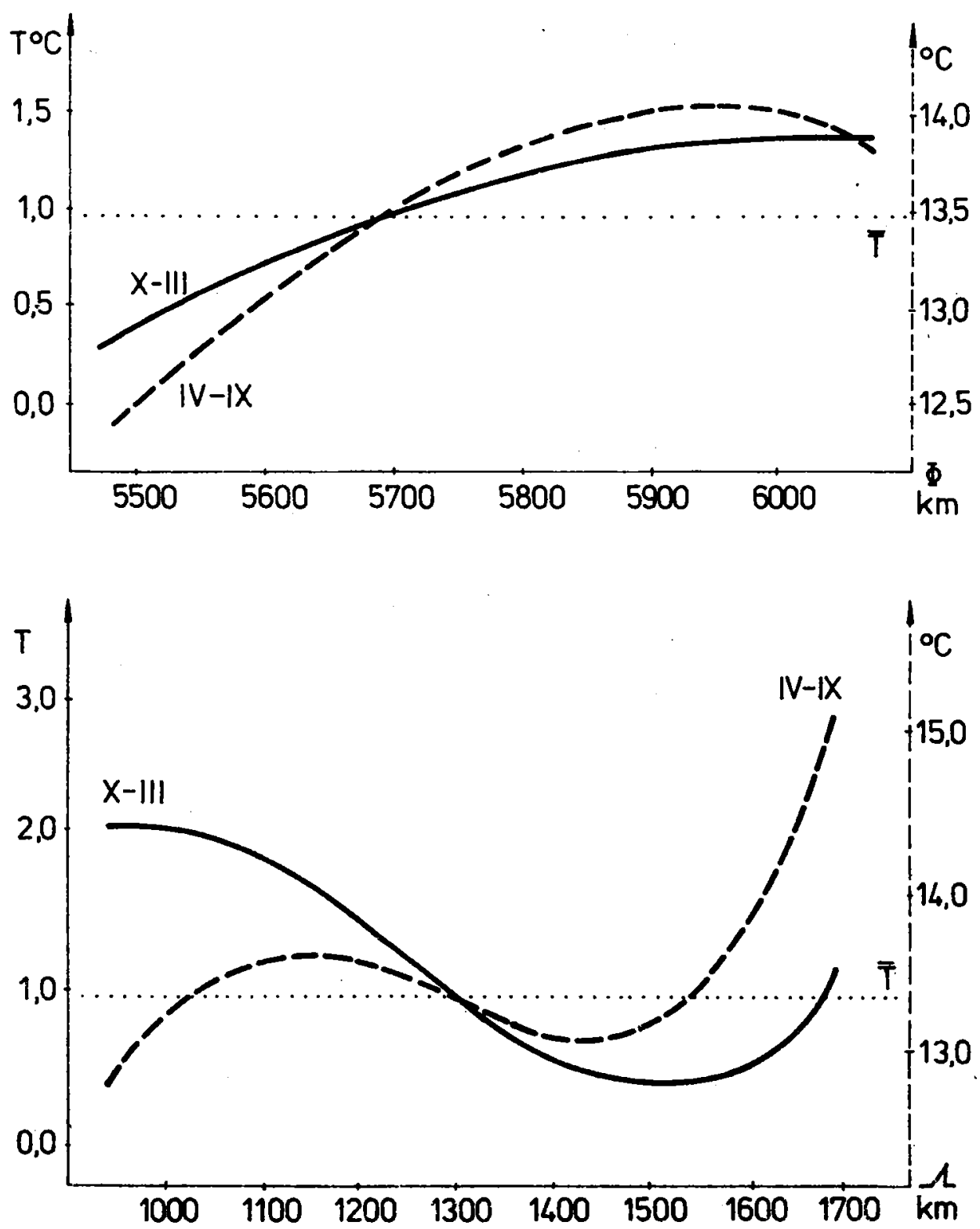

Fig. 1. Profiles: meridional $T(\Phi)$, parallel $T(\Lambda)$ of air temperature in Poland 

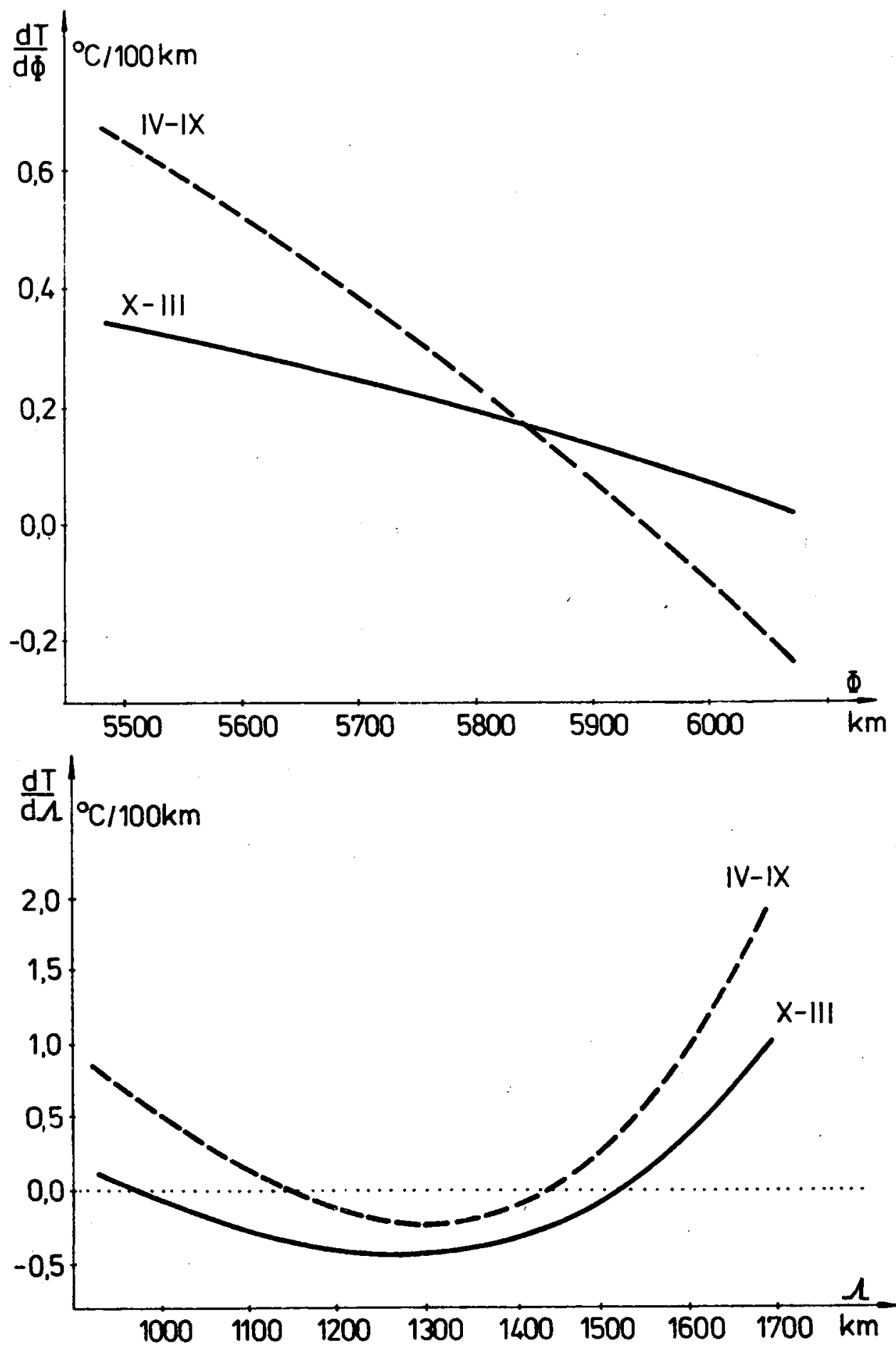
Fig. 2. Horizontal profiles of gradient: meridional $\frac{d T}{d \Phi}$ and $\frac{d T}{d \Lambda}$ parallel of air temperature in
Poland 

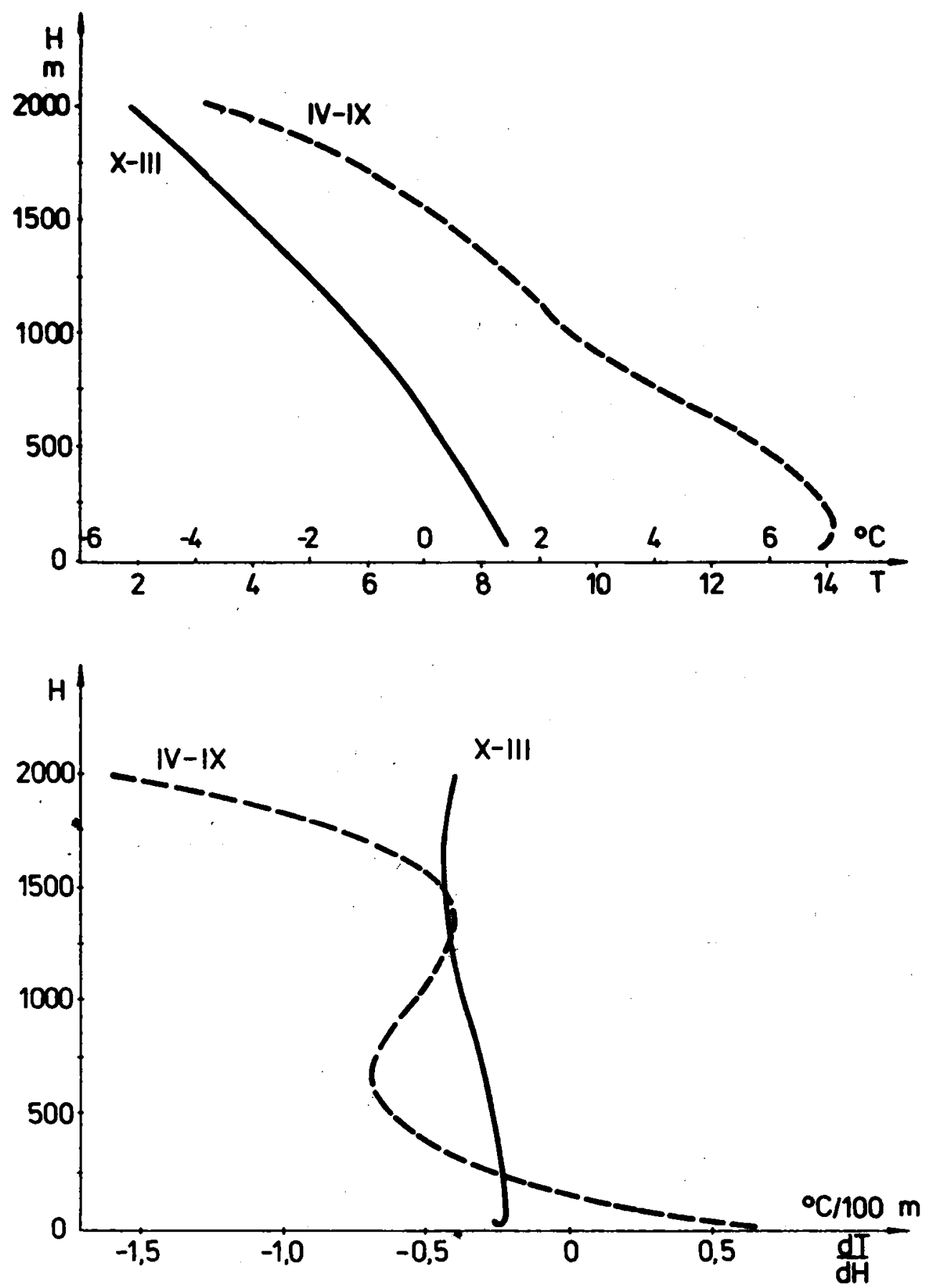

Fig. 3. Vertical profiles: $T(H)$ and hypsometric gradient of air temperature in Poland 
Meridional gradient $\frac{d T}{d \Phi}$ decreases with the growth from $0.35^{\circ} \mathrm{C} / 100 \mathrm{~km}$ - cool period and $0.67^{\circ} \mathrm{C} / 100 \mathrm{~km}$ - warm period on the southern border of Poland $\left(\varphi=55^{\circ}\right)$ to below zero - on the northern border $\left(\varphi=49^{\circ}\right)$. Parallel gradient for both periods changes sign from minus in central Poland to plus in western and eastern parts. Close to the western border $\left(\lambda=14^{\circ}\right)$ the temperature in the warm period increases toward the east by $1^{\circ} \mathrm{C} / 100 \mathrm{~km}$, and close to the eastern border $\left(\lambda=24^{\circ}\right)$ by circa $2^{\circ} \mathrm{C} / 100 \mathrm{~km}$.

In the vertical profile of hypsometric gradient $\frac{d T}{d H}$ the greatest temperature drops occur close to the sea level $(H=0):-0.2^{\circ} \mathrm{C} / 100 \mathrm{~km}$ - cool period, $0.7^{\circ} \mathrm{C} / 100 \mathrm{~m}$ - warm period. The most characteristic feature of $\frac{d T}{d H}$ profile in the warm period are two local extremes: maximum $-0.7^{\circ} \mathrm{C} / 100 \mathrm{~m}$ at about $600 \mathrm{~m}$ above the sea level and minimum $-0.4^{\circ} \mathrm{C} / 100 \mathrm{~m}$ at $1300 \mathrm{~m}$ above the sea level. With further increase of altitude the temperature drops in $100 \mathrm{~m}$ increase to $-1,5^{\circ} \mathrm{C} / 100 \mathrm{~m}$ at $2000 \mathrm{~m}$ above the sea level.

The deformation of temperature field due to relief is measured by the difference between gradient $\left[a_{1}, a_{2}, a_{3}\right]$ - according to regression hyperplane and gradient $\left[A_{1}, A_{2}\right]-$ according to regression plane (excluding $H$ ). Coordinates of these vectors in the territory of Poland show sinusoidal changes (Fig. 4).

Meridional gradient $\frac{\partial T}{\partial \varphi}=a_{1}$ is always negative - temperature drops toward the north. It changes from $-0.2^{\circ} \mathrm{C} / 1^{\circ}$ in December to $-0.6^{\circ} \mathrm{C} / 1^{\circ} \varphi$ in June, and its annual amplitude is $0.2^{\circ} \mathrm{C} / 1^{\circ} \varphi$. Parallel gradient $\frac{\partial T}{\partial \lambda}=a_{2}$ changes sign within the year: from minus in the cool period $\left(a_{2}<0\right)$ to plus $\left(a_{2}>0\right)$ in the warm period. Its annual mean value is close to zero, and the amplitude is $0.2^{\circ} \mathrm{C} / 1^{\circ} \lambda$. Temperature in October-March season increases westward - in January by over $0.2^{\circ} \mathrm{C} / 1^{\circ} \lambda$ and in April-September it increases eastward. The negative sign of parallel gradient indicates the predominance of Ocean climate characteristics in western part of Poland, the positive one - the predominancel of continental features in the east (dash-lined area of the map, Fig 6).

Moreover, annual changes of temperature field gradient $\left[A_{1}, A_{2}\right]$ have been shown according to regression plane (broken line). The annual course of meridional gradient $\frac{\partial T}{\partial \varphi}=A_{1}$ is totally different, as it remains positive throughout the year. The noticeable warming up toward the north is due to field deformation due to relief. 


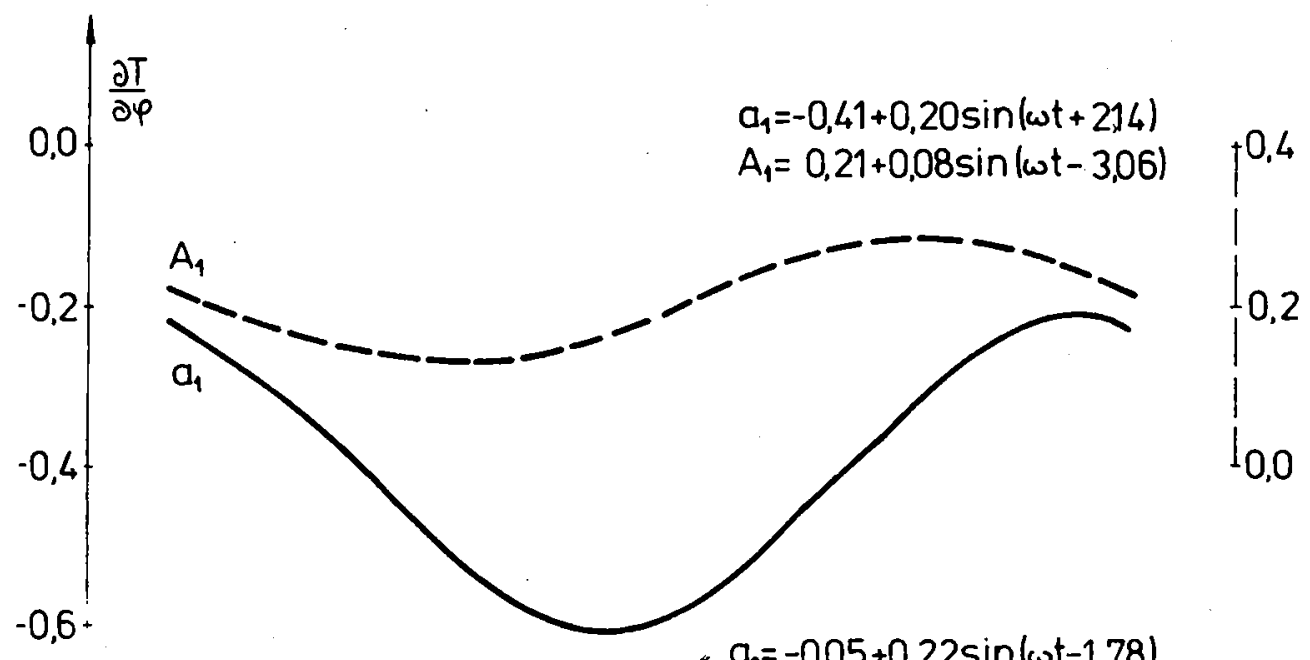

$a_{2}=-0,05+0,22 \sin (\omega t-1,78)$

$A_{2}=0,00+0,23 \sin (\omega t-1,76)$

$0,2+\frac{\partial T}{\partial \lambda}$

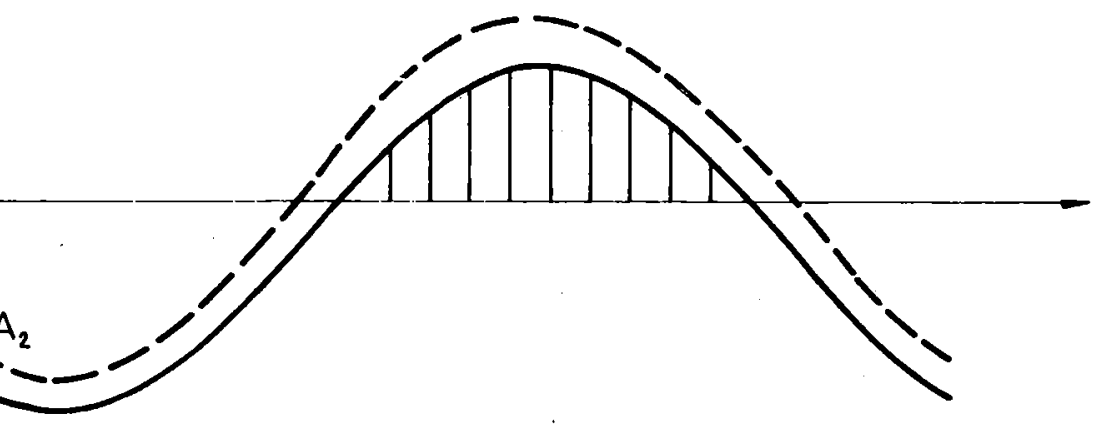

$a_{2}$

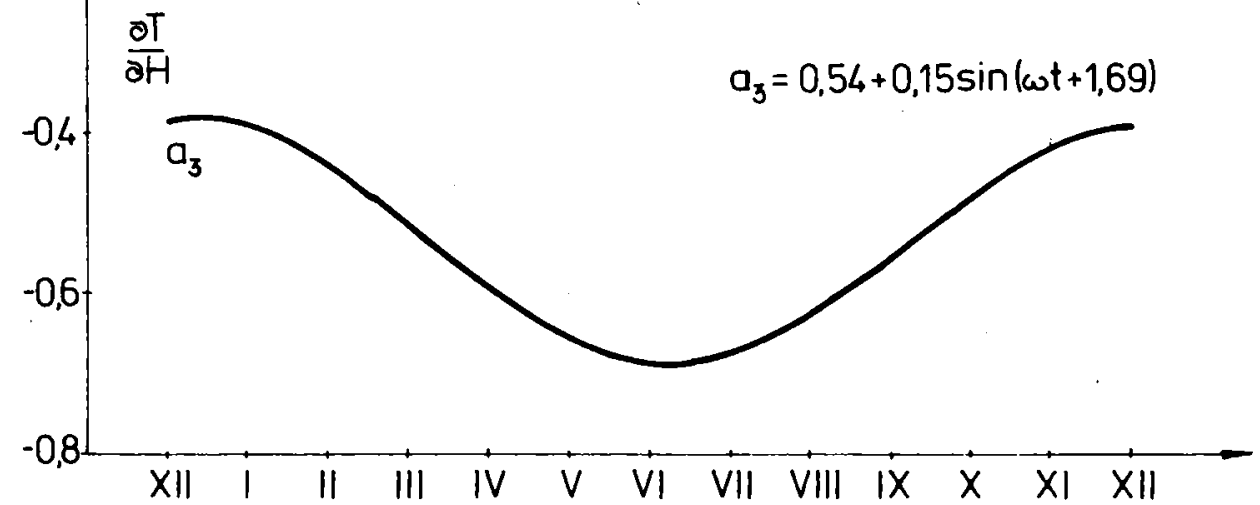

Fig. 4. Sinusoids of annual changes of horizontal gradient $\vec{\Gamma}=\left[a_{1}, a_{2}\right], \vec{\gamma}=\left[A_{1}, A_{2}\right]$ and hypsometric gradient $\frac{\partial T}{\partial \mathrm{H}}=a_{3}$ of air temperature $(\omega=0.0172)$. 
Table 2

Equations of regression hyperplane of the 4 th order of air temperature in relation to $\Phi, \Lambda, H$ ( $R$ - multiple correlation coefficient, $F$ - Fisher test)

$$
\begin{array}{rllll}
T= & 0.000002 \Phi & -0.000105 \Lambda & -0.006167 \mathrm{H} & +0.008391 \Phi^{2}+ \\
& -0.002462 \Phi \Lambda & -0.000814 \Phi \mathrm{H} & -0.001258 \Lambda^{2} & -0.000960 \Lambda \mathrm{H}+ \\
& -0.001175 \mathrm{H}^{2} & -0.000714 \Phi^{3} & +0.000444 \Phi^{2} \Lambda & +0.006919 \Phi^{2} \mathrm{H}+ \\
& +0.001912 \Phi \Lambda^{2} & -0.017240 \Phi \Lambda \mathrm{H} & -0.030970 \Phi \mathrm{H}^{2} & +0.001428 \Lambda^{3}+ \\
& -0.008364 \Lambda^{2} \mathrm{H} & -0.010290 \Lambda \mathrm{H}^{2} & -0.005889 \mathrm{H}^{3} & +0.000009 \Phi^{4}+ \\
& -0.000025 \Phi^{3} \Lambda & -0.000117 \Phi^{3} \mathrm{H} & +0.000103 \Phi^{2} \Lambda^{2} & +0.000265 \Phi^{2} \Lambda \mathrm{H}+ \\
& +0.000523 \Phi^{2} \mathrm{H}^{2}-0.000480 \Phi \Lambda^{3} & +0.000303 \Phi \Lambda^{2} \mathrm{H} & -0.000073 \Phi \Lambda \mathrm{H}^{2} \\
& +0.000224 \Phi \mathrm{H}^{3} & +0.000562 \Lambda^{4} & -0.000530 \Lambda^{3} \mathrm{H} & +0.001464 \Lambda^{2} \mathrm{H}^{2}+ \\
& -0.000037 \Lambda \mathrm{H}^{3} & -0.000199 \mathrm{H}^{4} & +18.38 & \\
& \multicolumn{5}{c}{\mathrm{Warm} \operatorname{period}(R=0.983, F=238.0)} \\
T= & 0.000005 \Phi & -0.000062 \Lambda & -0.000079 \mathrm{H} & +0.000052 \Phi^{2}+ \\
& -0.00099 \Phi \Lambda & -0.000113 \Phi \mathrm{H} & -0.000283 \Lambda^{2} & -0.000055 \Lambda \mathrm{H}+ \\
& -0.000033 \mathrm{H}^{2} & -0.000442 \Phi^{3} & +0.003853 \Phi^{2} \Lambda & -0.003207 \Phi^{2} \mathrm{H}+ \\
& -0.006399 \Phi \Lambda^{2} & -0.001288 \Phi \Lambda \mathrm{H} & -0.000929 \Phi \mathrm{H}^{2} & -0.004576 \Lambda^{3}+ \\
& -0.000650 \Lambda^{2} \mathrm{H} & -0.000192 \Lambda \mathrm{H}^{2} & -0.000088 \mathrm{H}^{3} & +0.000019 \Phi^{4}+ \\
& -0.000300 \Phi^{3} \Lambda & +0.000144 \Phi^{3} \mathrm{H} & +0.001746 \Phi^{2} \Lambda^{2} & -0.001134 \Phi^{2} \Lambda \mathrm{H}+ \\
& -0.000036 \Phi^{2} \mathrm{H}^{2}-0.004896 \Phi \Lambda^{3} & +0.004740 \Phi \Lambda^{2} \mathrm{H}+0.000547 \Phi \Lambda \mathrm{H}^{2}+ \\
& +0.000036 \Phi \mathrm{H}^{3} & +0.005576 \Lambda^{4} & -0.006451 \Lambda^{3} \mathrm{H} & -0.000641 \Lambda^{2} \mathrm{H}^{2} \\
& -0.000419 \Lambda \mathrm{H}^{3} & +0.000160 \mathrm{H}^{4} & +22.77 &
\end{array}
$$$$
\begin{array}{rllll}
T= & 0.000003 \Phi & -0.000082 \Lambda & -0.003176 \mathrm{H} & +0.004296 \Phi^{2}+ \\
& -0.001300 \Phi \Lambda & -0.000471 \Phi \mathrm{H} & -0.000777 \Lambda^{2} & -0.000516 \Lambda \mathrm{H}+ \\
& -0.000614 \mathrm{H}^{2} & -0.000570 \Phi^{3} & +0.002127 \Phi^{2} \Lambda & +0.001915 \Phi^{2} \mathrm{H}+ \\
& -0.002114 \Phi \Lambda^{2} & -0.009415 \Phi \Lambda \mathrm{H} & -0.016210 \Phi \mathrm{H}^{2} & +0.001486 \Lambda^{3}+ \\
& -0.004577 \Lambda^{2} \mathrm{H} & -0.005329 \Lambda \mathrm{H}^{2} & -0.003038 \mathrm{H}^{3} & +0.001407 \Phi^{4}+ \\
& -0.000161 \Phi^{3} \Lambda & +0.000011 \Phi^{3} \mathrm{H} & +0.000908 \Phi^{2} \Lambda^{2} & -0.000408 \Phi^{2} \Lambda \mathrm{H}+ \\
& +0.000250 \Phi^{2} \mathrm{H}^{2} & -0.002640 \Phi \Lambda^{3} & +0.002423 \Phi \Lambda^{2} \mathrm{H}+0.000220 \Phi \Lambda \mathrm{H}^{2}+ \\
& +0.000095 \Phi \mathrm{H}^{3} & +0.003004 \Lambda^{4} & -0.003354 \Lambda^{3} \mathrm{H} & +0.000466 \Lambda^{2} \mathrm{H}^{2} \\
& -0.000238 \Lambda \mathrm{H}^{3} & -0.000015 \mathrm{H}^{4} & +19.88 &
\end{array}
$$

Hypsometrio gradient $\frac{\partial T}{\partial H}=a_{3}$ ranges from $-0.4^{\circ} \mathrm{C} / 100 \mathrm{~m}$ in January to $-0.7^{\circ} \mathrm{C} / 100 \mathrm{~m}-$ in June.

The question of general temperature field deformation due to Poland's relief may be described (on the basis of data gathered in the years 1951-60 by 322 stations) by the following equations of regression hyperplanes:

$\begin{array}{llll}\text { Oct-March } & T= & 25.21-0.331 \Phi-0.316 \Lambda-0.383 H & 0.92 \\ \text { April-Sept } & T= & 32.54-0.325 \Phi+0.082 \Lambda-0.598 H & 0.96 \\ \text { Jan-Dec } & T= & 28.89-0.328 \Phi-0.118 \Lambda-0.490 H & 0.96\end{array}$


in relation to $\Phi, \Lambda, H$ and by the equations of regression planes

$\begin{array}{lll}\text { Oct-March } & T=-0.45+0.084 \Phi-0.253 \Lambda & 0.45 \\ \text { April-Sept } & T=-7.49+0.322 \Phi+0.180 \Lambda & 0.33 \\ \text { Jan-Dec } & T=-3.93+0.202 \Phi-0.037 \Lambda & 0.32\end{array}$

Horizontal gradients $\cdot \vec{\Gamma}=\left[a_{1}, a_{2}\right]$ and $\vec{\gamma}=\left[A_{1}, A_{2}\right]$ (in ${ }^{\circ} \mathrm{C} / 100 \mathrm{~km}$ ) have been vectorally presented in Fig. 5. These vectors are deflected from $S$ direction by angles $a, A$

\begin{tabular}{lcccl} 
& $a$ & $A$ & $A-a$ & \multicolumn{1}{c}{$D$} \\
Oct-March/cool period & $43.7^{\circ}$ & $108.4^{\circ}$ & $64.7^{\circ}$ & $35.9 \%$ \\
April-Sep/warm period & 345.8 & 209.2 & -136.6 & 75.9 \\
Jan-Dec/year & 19.8 & 169.6 & 149.8 & 83.2
\end{tabular}

Horizontal temperature gradient $\vec{\Gamma}$ in the cool period is deflected from $S$ direction by angle $a=43.7^{\circ}$ toward the west under the influence of predominantly maritime polar air masses (influence of the Atlantic). In the warm period this gradient is deflected from $S$ direction by $-14.2^{\circ}$ eastward, thus manifesting the increased continental charactersitics of the climate in the eastern part of Poland. It is the real horizontal gradient of temperature field described by regression hyperplane equation taking into account temperature drop $\frac{\partial T}{\partial H}=a_{3}$ with the increase of height above the sea level $H$. One should also note that air temperature is negatively correlated with altitude $H$ which in Poland decreases with increase of latitude.

Table 3

Equations of regression hyperplanes of the 4 th order of air temperature in relation to

$$
\begin{aligned}
& \text { Cool period }(R=0.614, F=5.116) \\
& T=+0.000047 \Phi \quad+0.000268 \Lambda+0.001386 \Phi^{2}-0.000401 \Phi \Lambda \\
&-0.001397 \Lambda^{2} \quad-0.000014 \Phi^{3}+0.018650 \Phi^{2} \Lambda-0.026 \dot{1} 10 \Phi \Lambda^{2}+ \\
&-0.018970 \Lambda^{3}+0.000020 \Phi^{4}-0.000514 \Phi^{3} \Lambda+0.001960 \Phi^{2} \Lambda^{2}+ \\
&-0.004713 \Phi \Lambda^{3}+0.006102 \Lambda^{4}-126.6 \\
& T=+0.000078 \Phi \quad \text { Warm period }(R=0.642, F=5.917) \\
&-0.002855 \Lambda^{2} \quad-0.000534 \Lambda+0.002790 \Phi^{2}-0.000896 \Phi \Lambda+ \\
&-0.038630 \Lambda^{3} \quad+0.000049 \Phi^{4}-0.035040 \Phi^{2} \Lambda-0.05400 \Phi \Lambda^{2}+ \\
&+-0.011550 \Phi \Lambda^{3}+0.014280 \Lambda^{4}-204.5 \\
& T=+0.000062 \Phi \quad+0.000399 \Lambda+0.002078 \Phi^{3} \Lambda+0.004759 \Phi^{2} \Lambda^{2} \\
&-0.002115 \Lambda^{2} \quad-0.000141 \Phi^{3}+0.026750 \Phi^{2} \Lambda-0.03989 \Phi \Phi \Lambda^{2}+ \\
&-0.028650 \Lambda^{3}+0.000034 \Phi^{4}-0.000816 \Phi^{3} \Lambda+0.003349 \Phi^{2} \Lambda^{2}+ \\
&-0.008104 \Phi \Lambda^{3}+0.010150 \Lambda^{4}-165.6
\end{aligned}
$$


$x-111$

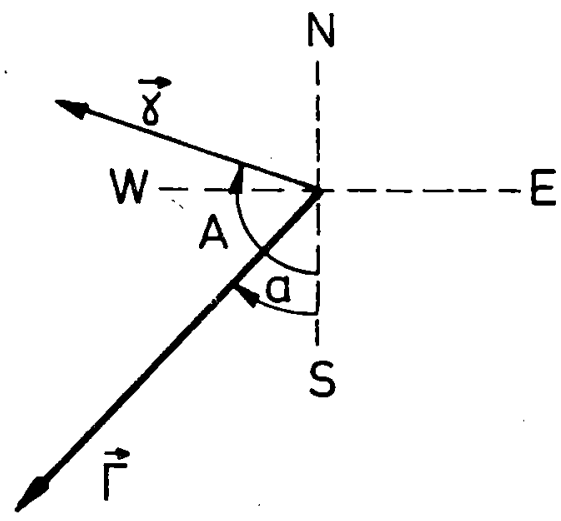

IV-IX

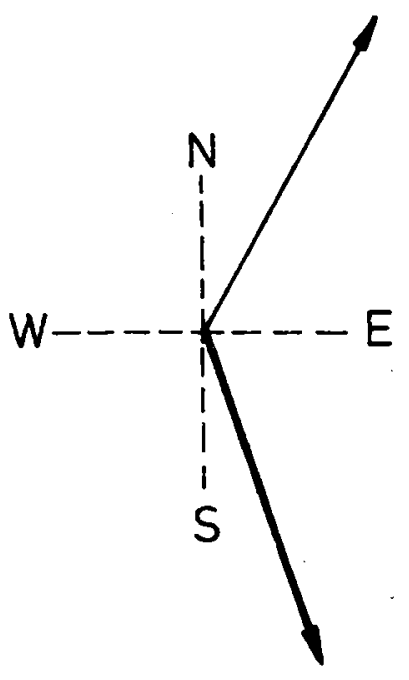

$|-x| \mid$

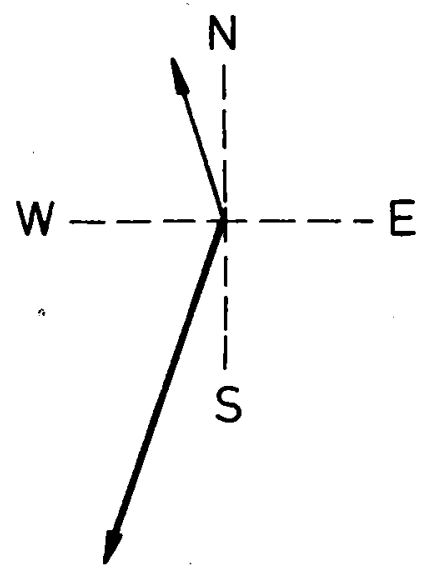

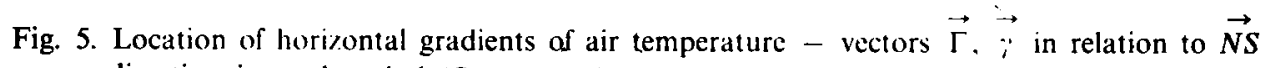
direction in cool period (Oct-March), warm period April-Sept) and year 
Horizontal gradient $\vec{\gamma}=\left[A_{1}, A_{2}\right]$ of air temperature according to regression plane describes the field deformed by the surface relief of the Earth. It forms the following angles with $S$ direction: $A=108.4^{\circ}-$ cool period, $A=209.2^{\circ}$ - warm period. The influence of relief on temperature field is greater during the warm period than during the cool period. The deformation coefficient $D$ for cool period is $D=35.9 \%$ and for warm period $D=75.9 \%$.

Finally, on the basis of regression hyperplane, i.e. 4th order polynomial with respect to $\Phi, \Lambda, H$, components of horizontal gradient of air temperature $\vec{\Gamma}=\left[\frac{\partial T}{\partial \Phi} \frac{\partial T}{\partial \Lambda}\right]$ have been calculated for various points in Poland. Location of vectors in relation to the meridian during the cool period is shown on the map (Fig. 6). Besides, the map represents horizontal temperature gradients (vectors of appropriate length) as well as isolines $a=$ const - of the angle in relation to $N S$ direction.

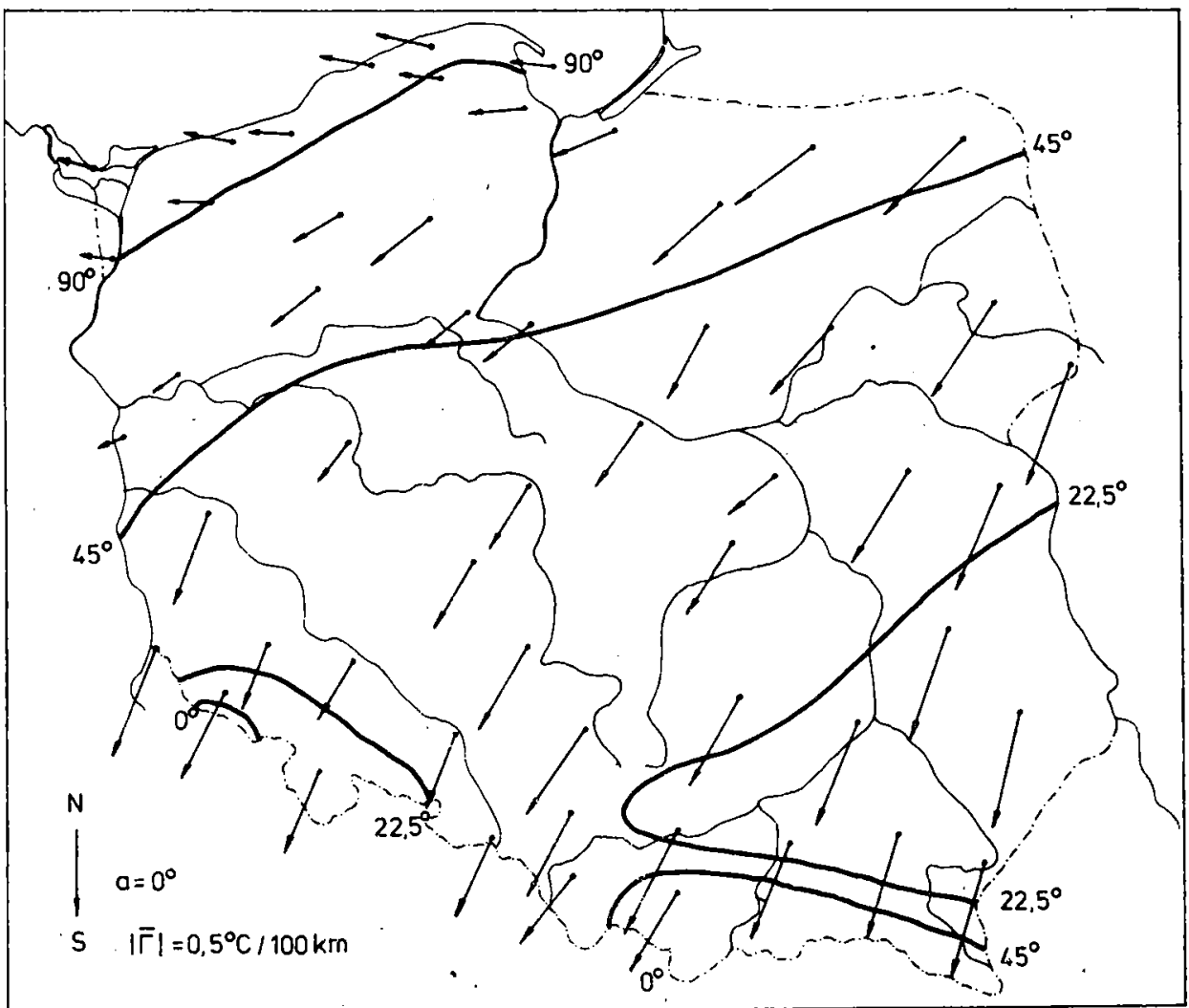

Fig. 6. Zones of the greatest and the least effect of maritime polar air masses on air temperature field in Poland 
Horizontal gradient of air temperature in cool period has the following characteristics:

- deflection from $S$ direction increases towards the north-west border of Poland $(a>0)$;

- its length (in ${ }^{\circ} \mathrm{C} / 100 \mathrm{~km}$ ) increases towards south-east border;

- at the Baltic coastline it changes direction from south-west to north-west $\left(a>90^{\circ}\right)$.

Thus, it follows that the territory of Poland during the cool period (Oct-March) is situated in the zone of predominantly maritime polar air to the disadvantage of continental-polar one. A weaker influence of the Atlantic on temperature field in south-east direction is manifested by the relatively shorter vectors $\vec{\Gamma}$ in the north-east.

The area of the greatest thermal influence of the Baltic sea is described by isoline $a=90^{\circ}$ which spreads along the coastline. On the other hand, isoline $a=45^{\circ}$ may be considered as the borderline of the greatest influence of the Atlantic and of the Baltic on air temperature field in Poland. South-east Poland belongs to the territory where martitime polar air masses have the least impact $\left(a<22,5^{\circ}\right)$.

One should emphasize the fact that the determination of temperature field deformation as due to relief has made it possible to distinguish various zones of influence of martime polar air masses on the climate of Poland.

\section{REFERENCES}

B o r y c z k a, J., 1984, Model deterministyczno-stochastyczny wielookresowych zmian klimatu (A deterministic-stochastic model of long-term climate changes), Warszawa.

Boryczka, J., Stopa-Boryczka M., Wawe r J., 1984, Aproksymacja pola temperatury powietrza w Polsce (Approximation of field of air temperature in Poland), Contribution of Polish science to the World Climatological Programme, Skierniewice.

S t o p a - B o r y c z k a, M., 1973, Cechy termiczne klimatu Polski (Thermal features of Poland climate), Warszawa.

S t o pa-Bor y z ka, M., B oryczka, J. 1974-part I, 1976-part II, 1983-part III, 1980-part IV, Atlas wspólzależności parametrów meteorologicznych i geograficznych w Polsce (Atlas of interpendences of meteorological and geographical parameters in Poland), Warszawa.

E we r t, A., 1984, Opady atmosferyczne na obszarze Polski w przekroju rocznym (Precipitation in Poland in year section), Wyd. Słupskie, Słupsk. 
